\title{
Prevention of gastrointestinal tumors based on adenomatous polyposis coli gene mutation by dendritic cell vaccine
}

\author{
Toshio linuma, ${ }^{1,2}$ Sadamu Homma, ${ }^{1,2}$ Tetsuo Noda, ${ }^{3}$ Donald Kufe, 4 \\ Tsuneya Ohno, ${ }^{2}$ and Gotaro Toda ${ }^{1}$
}

\begin{abstract}
${ }^{1}$ Division of Gastroenterology and Hepatology, Department of Internal Medicine, and 2Department of Oncology, Institute of DNA Medicine, Jikei University School of Medicine, Minato-ku, Tokyo, Japan. ${ }^{3}$ Department of Cell Biology, Cancer Institute, Toshima-ku, Tokyo, Japan. ${ }^{4}$ Dana-Farber Cancer Institute, Harvard Medical School, Boston, Massachusetts, USA.
\end{abstract}

\begin{abstract}
Here we describe the effect of immunization with dendritic cells loaded with syngeneic tumor cells (DC/Ts) by polyethylene glycol treatment, on tumor development in adenomatous polyposis coli (APC) gene mutant mouse models, $A P C 1309$ and $A P C^{\mathrm{Min}-/^{+}}$, in which adenomatous polyps of the gastrointestinal tracts develop with a high incidence. Treatment with DC/Ts prevented the development of gastrointestinal tumors, and coadministration of DC/Ts and IL-12 caused a further reduction in tumor incidence. Splenocytes from APC1309 mice treated with DC/Ts and IL-12 showed no cytotoxic activity toward the tumor cells, but serum antibody specific to them was detected. IgG from the treated mice exhibited cytotoxic activity against the tumor cells in vitro. Predominance of Th2 cell response over Th1 response was also suggested by ELISPOT assays in the treated mice. Depletion in vivo of $\mathrm{CD}^{+} \mathrm{T}$ cells, not $\mathrm{CD8}^{+} \mathrm{T}$ cells, by the intraperitoneal administration of corresponding $\mathrm{mAb}$ 's decreased the antitumor effect of $\mathrm{DC} / \mathrm{T}$ inoculation. Immunofluorescence microscopic studies showed that Ig was attached to tumor cells in mice treated with DC/Ts and IL-12. These findings indicate that $\mathrm{DC} / \mathrm{T}$ vaccination prevents tumor development through $A P C$ gene mutation and that its preventive effects are mediated by humoral antitumor immunity.
\end{abstract}

\section{Introduction}

Development of colon cancer in humans is associated with genetic as well as environmental influences $(1,2)$. There are two welldefined forms of hereditary colorectal cancer: (a) familial adenomatous polyposis (FAP), caused by germline mutations in the adenomatous polyposis coli (APC) gene, and (b) hereditary nonpolyposis colorectal cancer, caused by germline mutations in mismatch-repair genes (2-5). These hereditary colorectal cancers are characterized by their early onset and high mortality. For example, in patients with FAP, adenomatous polyps develop by a median age of 16 years and progress to cancers by a median age of 39 years (2). Loss of APC function by gene mutation, which is the case in FAP, confers selective advantages that allow the initial clonal expansion on the intestinal cell and induces the genetic instability that allows for multiple hits on other genes responsible for tumor progression and malignant transformation, triggering the adenoma-carcinoma sequence (6). Mutation of the APC gene has also been observed in $70-80 \%$ of sporadic colon cancers (7). Thus, FAP is an ideal model for evaluating the efficacy of surgical and medical treatments for the prevention and regression of colon cancer and adenoma (8).

NSAIDs have been shown to prevent colon cancer in FAP patients as well as the FAP model mice, $A P C^{\text {Min- }-+}$ and $A P C 1309(8,9)$. However, the long-term ingestion of NSAIDs that is required to inhibit the development of colorectal cancer is frequently associated with adverse side effects, including gastrointestinal irritation and kidney

Nonstandard abbreviations used: dendritic cell (DC); dendritic cell loaded with syngeneic tumor cell (DC/T); familial adenomatous polyposis (FAP); phycoerythrin (PE); polyethylene glycol (PEG); tumor-associated antigen (TAA).

Conflict of interest: The authors have declared that no conflict of interest exists.

Citation for this article: J. Clin. Invest. 113:1307-1317 (2004).

doi:10.1172/JCI200417323. and platelet dysfunction $(10,11)$. Recent advances in immunology and increasing knowledge about tumor immunity are encouraging the development of various immunotherapies to eradicate tumors or prevent tumor development. Tumor-associated antigens (TAAs) have been identified that are recognized by specific $T$ cell receptors (12). The recognition of TAA peptides by CTLs can result in the rejection of tumors $(13,14)$. However, tumors use several mechanisms to escape CTL-mediated killing, including expression of Fas ligand and downregulation or modification of TAAs, the transporters of antigenic peptides or MHC class I molecules (15). Moreover, the acquisition of antitumor immunity can be abrogated by induction of peripheral tolerance and immune suppression through secretion of immune-suppressive cytokines (16). Thus, when spontaneous tumors have escaped immune recognition, strategies are needed to reverse immunological unresponsiveness and thereby induce antitumor immunity. One strategy for inducing antitumor immunity is the use of dendritic cells (DCs) loaded with tumor antigens to prime T cells (17).

DCs are potent APCs that express MHC class I, II, and costimulatory molecules essential for priming $\mathrm{CD}^{+}$and $\mathrm{CD}^{+} \mathrm{T}$ cells. Vaccination strategies based on DCs are being developed to induce antitumor immunity (17-21). Administration of DCs pulsed with antigenic peptides or transfected with genes encoding TAAs or with TAA RNA has been shown to induce specific immunity against transplanted tumors in animal models (22-25). In most cancers, however, TAAs are not identified. As an approach to load DCs with known or unidentified TAAs, DCs were pulsed with tumor lysates, transfected with tumor cell mRNA, or fused with tumor cells (26-28). Since human cancers develop as a result of the accumulation of genetic lesions, there is a need to evaluate vaccines based on DCs in genetic models of spontaneous, rather than transplanted tumors. 
In the present study, we used APC1309 mice and $A P C^{\mathrm{Min}-/+}$ mice as the models of spontaneous colorectal tumors, in which the $A P C$ gene had been mutated at codon 1309 and 850, respectively $(9,29)$. In these mice, multiple tumors develop in the stomach, duodenum, jejunum, ileum, cecum, and colon. Tumors develop at 3 weeks of age and, by 10 weeks, $80-120$ tumors are detectable throughout the gastrointestinal tract. APC1309 and APC Min-/+ mice were immunized with DCs loaded with tumor cells that had been derived from a spontaneous tumor of an APC1309 mouse. The results demonstrate that the inoculation of DCs loaded with the tumor cells prevents the development of tumors, and that the administration of IL-12 in combination with the inoculation causes existing tumors to regress. To our knowledge, this experiment represents the first success of an immunological treatment in the genetic models of colorectal tumor.

\section{Methods}

Mice and cell lines. C57BL/6J mice and $A P C^{\mathrm{Min}-/+}$ mice were purchased from Nihon SLC Co. Ltd. (Hamamatsu, Japan) and The Jackson Laboratory (Bar Harbor, Maine, USA), respectively. APC1309 KO mice with a $\mathrm{C} 57 \mathrm{BL} / 6 \mathrm{~J}$ genetic background carried a mutation at codon 1309 of the APC gene and were produced at the Cancer Institute in Tokyo (9). BALB/c mice were purchased from Nihon SLC Co. Ltd. All of the experimental procedures were carried out in accordance with Jikei University guidelines on animal welfare.

In $A P C^{\mathrm{Min}-/+}$ mice, the offspring were characterized for the $A P C$ genotype by PCR according to Dietrich et al. (29). In APC1309 mice, the APC genotype of the offspring was determined at 4 weeks of age. DNA extracted from the tail was amplified by PCR. Forty cycles were performed, using the following cycling conditions: $94^{\circ} \mathrm{C}$ for $1 \mathrm{~min}-$ ute, $62^{\circ} \mathrm{C}$ for 2 minutes, $72^{\circ} \mathrm{C}$ for 2 minutes, and a final extension at $72^{\circ} \mathrm{C}$ for 4 minutes. To increase the specificity of PCR amplification, the 'hot start' method was used: an initial denaturation of the reaction mixture containing all reagents except the enzyme for 3 minutes at $94^{\circ} \mathrm{C}$. Nucleotide sequences of primers were as follows: APC sense, 5'-TCAAGGTGCAGTTCATTATCATCACTG-3', wild APC antisense, $5^{\prime}$-CTTCAGTTGCAGGATCTTCAGCTGACC-3' (product size, $153 \mathrm{bp}$ ); mutant APC sense, 5'-TCAAGGTGCAGTTCATTATCATCACTG-3', antisense, 5'-GCTAAAGCGCATGCTCCAGACTGCCTTG-3' (product size, $243 \mathrm{bp}$ ). The mice for which the analysis of PCR products showed both 153-bp and 243-bp products were selected for use in the experiments.

The murine hepatoma cell line Hepa1-6, the murine melanoma cell line B16, and the mouse YAC-1 cell line were obtained from ATCC (Manassas, Virginia, USA). The murine colorectal cancer cell line MC38 was a gift from D. Kufe.

Generation of DC/Ts. Bone marrow DCs were prepared as described by Inaba et al. (30,31). Their phenotypic characterization has been reported elsewhere (32). A cell line designated as tumor $\mathrm{T}$ was established from an intestinal tumor of the APC1309 mouse at the Cancer Institute in Tokyo (9). Tumor T cells showed aneuploi$\mathrm{dy}$, and their population-doubling time was 24 hours. However, they showed no tumorigenicity in syngeneic C57BL/6J mice when inoculated subcutaneously or intravenously.

DC/Ts were generated by treating DCs and tumor T cells with polyethylene glycol (PEG) (Sigma-Aldrich, St. Louis, Missouri, USA) to fuse them, as described elsewhere $(28,32,33)$. Briefly, DCs and tumor $\mathrm{T}$ cells were mixed at a ratio of 2:1 and treated with 50\% PEG at $37^{\circ} \mathrm{C}$ for 1 minute. After PEG had been removed by RPMI-1640 medium (Nissui Pharmaceutical Co., Tokyo, Japan) and centrifuga- tion at $250 \mathrm{~g}$, the cells were incubated in RPMI-1640 medium containing $10 \mathrm{ng} / \mathrm{ml}$ recombinant murine granulocyte/macrophage CSF (supplied by Kirin Brewery Co., Tokyo, Japan) and $50 \mathrm{U} / \mathrm{ml}$ recombinant murine IL-4 (BD Bioscience, San Jose, California, USA) overnight at $37^{\circ} \mathrm{C}$. Nonadherent and loosely attached cells were collected by aspiration and centrifugation, and used for inoculation as DC/Ts. The number of DC/Ts inoculated was expressed as the number of DCs that were used for loading with the tumor cells. For assessment of DC/T generation, DCs and tumor T cells were stained with FITC-conjugated hamster anti-mouse CD80 mAb's (PharMingen, San Diego, California, USA) and Red Fluorescent Cell Linker Kit for General Cell Membrane Labeling PKH26GL (Sigma-Aldrich), respectively, treated with PEG, cultured overnight, and collected as described earlier. As a control, stained DCs and tumor cells that had not been treated with PEG were also cultured in the same medium and collected after overnight incubation. Generation of DC/Ts was assessed by FACS (FACSCalibur, BD Bioscience Immunocytometry Systems, San Jose, California, USA) analysis and fluorescence microscopy (LSM410; Carl Zeiss, Oberkochen, Germany).

Phenotypes of DCs and DC/Ts were compared by flow-cytometric analysis using FITC-conjugated anti-mouse $\mathrm{H}-2 \mathrm{~K}^{\mathrm{b}}, \mathrm{I}-\mathrm{A}^{\mathrm{b}}, \mathrm{CD} 80$, and CD86 mAb's, which were purchased from PharMingen.

DCs $\left(5 \times 10^{5}\right)$ and DC/Ts $\left(5 \times 10^{5}\right)$ were cultured for 48 hours in a final volume of $1 \mathrm{ml}$ RPMI-1640 medium containing $1 \mu \mathrm{g} / \mathrm{ml} \mathrm{LPS}$ (Sigma-Aldrich). The supernatants were assayed for IL-12, IL-6, and IL-10 by ELISA kits (BioSource International, Camarillo, California, USA) according to the manufacturer's instructions.

Treatment of mice and enumeration of the tumors. DC/Ts were injected at a dose of $1 \times 10^{6}$ cells per mouse into the tail vein at 6 and 8 weeks of age. IL-12 (supplied by Genetics Institute, Cambridge, Massachusetts, USA) was administered at a dose of $0.5 \mu \mathrm{g} / \mathrm{mouse}$ intraperitoneally at 5 and 10 days after the first injection of DC/Ts and 1 week after the last injection of DC/Ts. In this experimental design, some mice were treated with PBS or a mixture of DCs and tumor T cells instead of DC/Ts, or PBS instead of IL-12. Other mice were inoculated with DCs and tumor T cells that had each been treated with PEG, incubated separately overnight, collected as described earlier, and then admixed immediately before injection. Mice were sacrificed at 10 weeks of age. Gastrointestinal tracts from the lower esophagus to the rectum were excised, fixed by infusion of formaldehyde from the rectum, cut open, and stained with Methylene Blue. The tumors in the entire gastrointestinal tract were counted under a microscope at 10 -fold amplification.

In some experiments, tumor T cells $\left(3 \times 10^{6}\right.$ cells per mouse) were subcutaneously injected into 8-week-old allogeneic BALB/c mice twice with a 1 -week interval, and the mice were sacrificed 1 week after the last injection.

In vivo depletion of $\mathrm{CD}^{+}$and $\mathrm{CD} 8^{+} \mathrm{T}$ cells. Anti-mouse CD4 mAb's (ATCC hybridoma GK1.5) or anti-mouse CD8 mAb's (ATCC hybridoma 56.6.73), which were donated by N. Watanabe (Department of Tropical Medicine, Jikei University School of Medicine, Tokyo, Japan), was administered at a dose of $0.5 \mathrm{mg} / \mathrm{mouse}$ intraperitoneally, 1 day before and 2 days after each of the DC/T inoculations, which were performed according to the experimental design described earlier. The mice were treated with IL-12 and sacrificed exactly as in the experimental design described earlier.

To examine whether the in vivo depletion of $\mathrm{CD}^{+}$and $\mathrm{CD}^{+} \mathrm{T}$ cells was affected, anti-mouse CD4 mAb's (ATCC hybridoma GK1.5) or anti-mouse CD8 mAb's (ATCC hybridoma 56.6.73) were administered to 8-week-old mice by intraperitoneal injection twice with an 

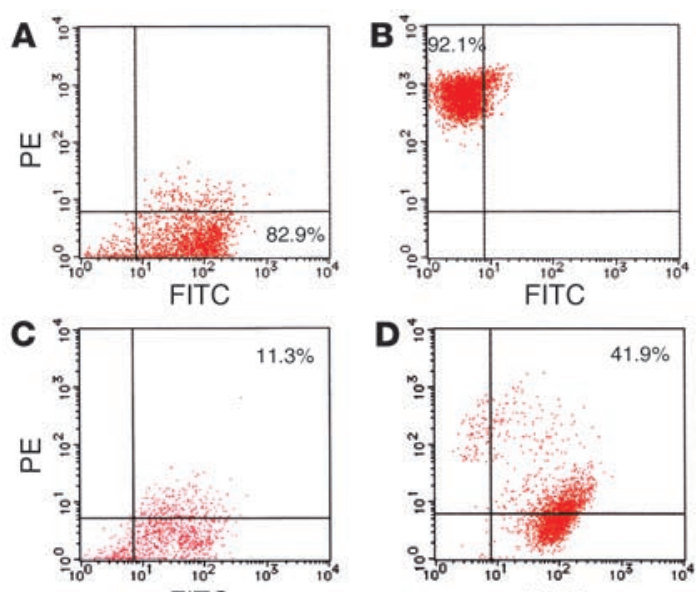

FITC
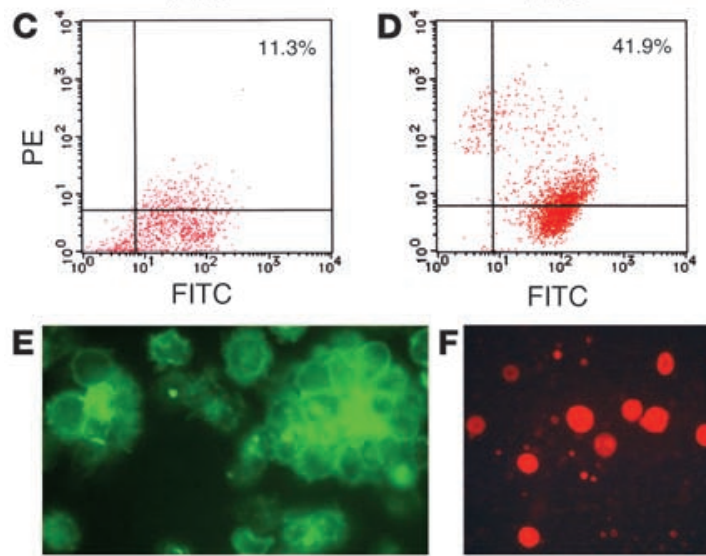

FITC

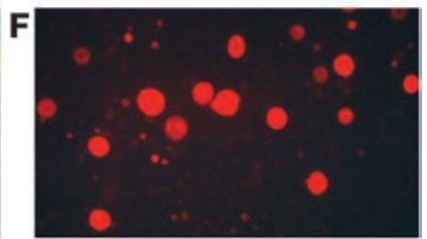

G
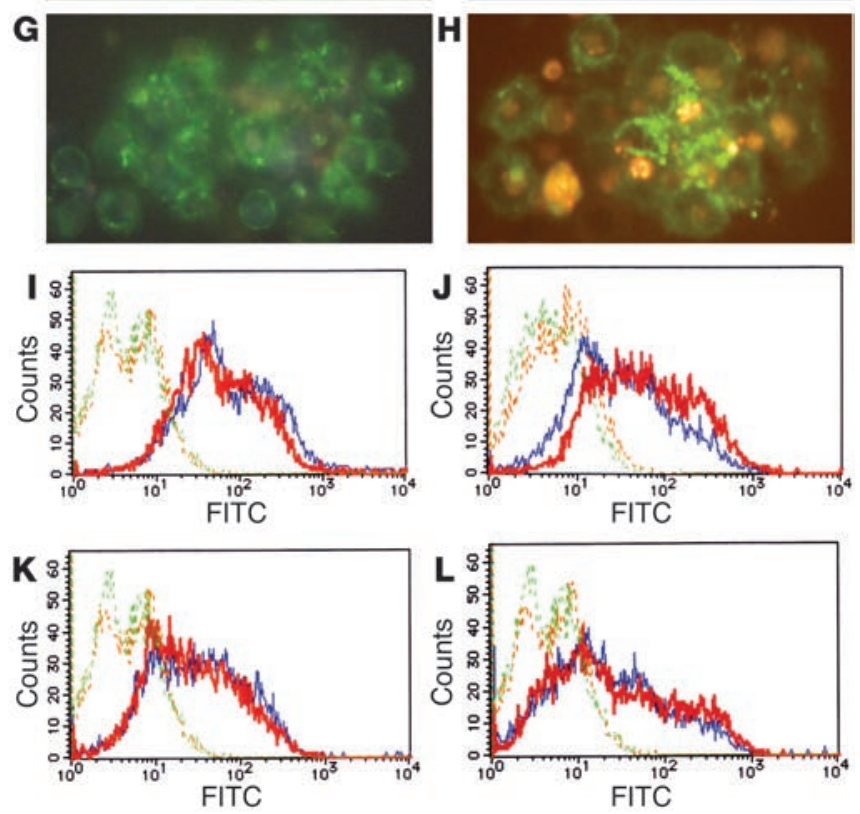

interval of 3 days. The mice were sacrificed 1, 3, and 6 days after the last injection, and their splenocytes were collected as described earlier. Identification of $\mathrm{CD}^{+}$and $\mathrm{CD}^{+} \mathrm{T}$ cells among the splenocytes was done with FACS using phycoerythrin-labeled (PE-labeled) R-M45 anti-CD4 mAb's (PharMingen) and 53-6.7 anti-CD8 mAb's (PharMingen), respectively. $\mathrm{CD}^{+}$and $\mathrm{CD}^{+} \mathrm{T}$ cells quantitated after the mAb's were compared with baseline levels established in the mice of the same age that received no injection of the mAb's.

Assay of cytotoxic activity of splenocytes toward tumor cells. Splenocytes obtained by gentle disruption of spleens on a steel mesh were cultured for 4 days in medium containing $50 \mathrm{U} / \mathrm{ml}$ of human recombinant IL-2. In some experiments, splenocytes were cultured for 4 days with DC/Ts or irradiated tumor T cells in the medium without IL-2 (stimulator/splenocyte ratio of 1:100). In other experiments, tumor $\mathrm{T}$

\section{Figure 1}

FACS analysis and fluorescence microscopy of DCs and tumor cells simply mixed or treated with PEG. DCs stained with FITC-conjugated anti-CD80 and tumor T cells stained with the red-fluorescent dye PKH26GL were mixed, treated with PEG or not, and incubated overnight as described in the text. A mixture of DCs and tumor cells that had not been treated with PEG served as control. After overnight incubation, the cells were collected, analyzed by FACS, and examined under a fluorescence microscope. FACS analysis results: (A) DCs stained with FITC-conjugated anti-CD80; (B) tumor cells stained with PKH26GL; (C) mixture of DCs and tumor cells; (D) PEG-treated DCs and tumor cells. Fluorescence microscopy: (E) DCs stained with FITC-conjugated anti-CD80; (F) tumor cells stained with PKH26GL; (G) mixture of DCs and tumor cells; (H) PEG-treated DCs and tumor cells. Six independent experiments were performed with similar results. A typical experiment is shown. FACS analysis of DCs and DC/Ts: DCs (blue solid line) and $\mathrm{DC} / \mathrm{T}$ (red solid line) were stained with FITC-conjugated $\mathrm{mAb}$ 's against (I) $\mathrm{H}-2 K^{b}$ (J) I-A $A^{b}$ K) CD80, and (L) CD86. Cells stained with FITC-conjugated isotype-matched control antibody are indicated by the dotted lines (green, DCs; orange, DC/Ts).

cells had been incubated with $3,000 \mathrm{U} / \mathrm{ml}$ recombinant murine IFN- $\gamma$ ) (TECHNE Corp., Minneapolis, Minnesota, USA) for 48 hours before examination of their susceptibility to lysis by splenocytes. The target cells, tumor T cells $\left(1 \times 10^{4}\right.$ cells/well $)$ that had been labeled with ${ }^{51} \mathrm{Cr}$, were incubated with the splenocytes at effector/target $(\mathrm{E} / \mathrm{T})$ ratios ranging from $20: 1$ to $80: 1$ at $37^{\circ} \mathrm{C}$ for 4 hours in $200 \mu$ l of RPMI- 1640 medium supplemented with $10 \%$ heat-inactivated FCS in a 96-well microplate. After the cells were spun down by centrifugation at $250 \mathrm{~g}$, $100 \mu \mathrm{l}$ of supernatant was collected for measurement of radioactivity. The cytotoxic activity of splenocytes against ${ }^{51} \mathrm{Cr}$-labeled YAC- 1 cells was examined as described for the examination of cytotoxic activity against tumor $\mathrm{T}$ cells.

In some experiments, splenocytes were prepared from BALB/c mice inoculated with tumor $T$ cells as described already, mixed with irradiated tumor $\mathrm{T}$ cells at a ratio of 100:1, and cultured in RPMI1640 medium containing $20 \mathrm{U} / \mathrm{ml}$ human recombinant IL-2 for 48 hours. Their cytotoxicity against ${ }^{51} \mathrm{Cr}$-labeled tumor $\mathrm{T}$ cells and MC38 cells was assayed at an E/T ratio of 80:1 as described earlier.

The percentage of specific ${ }^{51} \mathrm{Cr}$ release was calculated according to the following formula: percentage ${ }^{51} \mathrm{Cr}$ release $=100 \times$ [experimental release (cpm) - spontaneous release (cpm)] / [maximum release $(\mathrm{cpm})$ - spontaneous release $(\mathrm{cpm})]$. The maximum release was that obtained from target cells incubated with $0.33 \mathrm{~N}$ $\mathrm{HCl}$, and spontaneous release was that obtained from target cells incubated without the effector cells. All the determinations were carried out in triplicate.

Detection of antibody reactive with tumor cells. A 50- $\mu$ l aliquot of mouse serum diluted appropriately with PBS was added to the pellet of tumor T cells $\left(2 \times 10^{5}\right)$ and incubated at $4^{\circ} \mathrm{C}$ for 30 minutes. The cells were then washed twice with PBS and incubated with $2 \mu \mathrm{l}$ of an FITC-conjugated rat anti-mouse Ig polyclonal antibody, or a goat anti-mouse IgG1, IgG2a, IgA, or IgM antibody (PharMingen) at $4^{\circ} \mathrm{C}$ for 30 minutes under a light shield. The cells were washed twice with PBS, and their fluorescence intensities were measured by flow-cytometric analysis using FACS. Antibody activity was expressed by the median value of a whole fluorescence intensity histogram (median fluorescence intensity).

ELISPOT assays. Splenocytes were collected as described earlier from three groups of 10-week-old mice: untreated, treated with $\mathrm{DC} / \mathrm{Ts}$, and treated with DC/T + IL-12. Treatment of mice with 
A

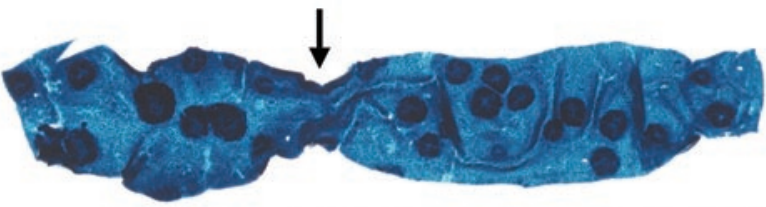

B

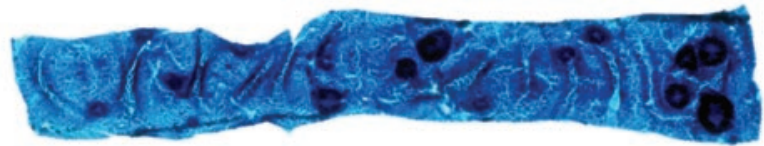

C

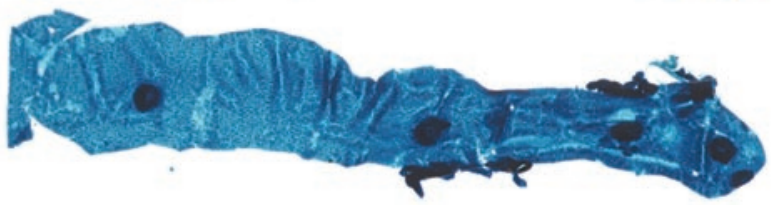

Figure 2

Macroscopic view of the upper ilei of APC1309 mice. The entire gastrointestinal tracts of 10-week-old mice were processed as described in the text. The upper ilei were excised and are shown here. The tumors are identified as black dots on the mucosa. The arrow indicates a stenotic change of the intestine by tumor growth in an untreated mouse. (A) Upper ileum from an untreated mouse (B) from a mouse treated with $\mathrm{DC} / \mathrm{Ts}$, and $(\mathbf{C})$ from a mouse treated with $\mathrm{DC} / \mathrm{T}+\mathrm{IL}-12$.

DC/Ts or DC/T + IL-12 was performed as described earlier. Cell fractions enriched with $\mathrm{CD}^{+}$or $\mathrm{CD}^{+} \mathrm{T}$ cells were prepared from the splenocytes with MACS magnetic sorting system (Miltenyi Biotec GmbH, Bergisch Gladbach, Germany) according to the manufacturer's instructions. They were then stimulated by culture with irradiated (100 Gy) tumor T cells or DC/Ts at a ratio of 200:1 for 4 days. The frequencies of $\mathrm{CD}^{+}$and $\mathrm{CD}^{+} \mathrm{T}$ cells secreting IL- 4 or IFN- $\gamma$ were determined using ELISPOT assay kits (R\&D Systems Inc., Minneapolis, Minnesota, USA) according to the manufacturer's instructions. $\mathrm{CD}^{+}$and $\mathrm{CD}^{+} \mathrm{T}$ cells cultured with irradiated tumor $\mathrm{T}$ cells or DC/Ts were placed at $10^{4}$ cells/well in ELISPOT wells and incubated overnight at $37^{\circ} \mathrm{C}$ according to the manufacturer's instructions. Spot-forming cells were enumerated under a stereoscopic microscope.

Purification of IgG from mice sera and assessment of its cytotoxic activity against tumor $T$ cells. Mouse IgG was purified from mice sera using the ImmunoPure IgG purification kit (Pierce Chemical Co.,

\section{Figure 3}

Effect of treatment with $\mathrm{DC} / \mathrm{Ts}$ on the development of gastrointestinal tumors in APC1309 and APC $\mathrm{Min}-/_{+}$mice. (A) Ten APC1309 mice were sacrificed at the start of treatment (6 weeks of age). Other groups of $A P C 1309$ mice that were untreated or treated with IL-12, with a mixture of PEG-treated DCs and PEG-treated tumor T cells (DC-PEG + $\mathrm{T}-\mathrm{PEG}$ ), with $\mathrm{DC} / \mathrm{Ts}$ alone, or with $\mathrm{DC} / \mathrm{T}+\mathrm{IL}-12$, were sacrificed at 10 weeks of age. The gastrointestinal tracts were processed as described in the text. The tumors in the entire gastrointestinal tracts were counted under the microscope. Each column represents mean \pm SD (error bar) of the number of tumors. ${ }^{*} P<0.05$; ${ }^{* *} P<0.001$. (B) Six $A P C^{\text {Min- } /+}$ mice were sacrificed at the start of treatment ( 6 weeks of age). Other groups of seven $A P C^{\mathrm{Min}-{ }^{+}}$mice, which were untreated or treated with IL-12, DC/Ts, or DC/T + IL-12, were sacrificed at 10 weeks of age. The tumors in the entire gastrointestinal tracts were counted as described for $\mathbf{A}$. Each column represents mean $\pm \mathrm{SD}$ (error bar) of the number of tumors. Figures in parentheses show the number of mice examined. ${ }^{\star} P<0.01 ;{ }^{* *} P<0.001$.

Rockford, Illinois, USA) according to the manufacturer's instructions. The concentration of purified IgG was determined using a protein assay kit (Bio-Rad Laboratories Inc., Hercules, California, USA) and a microplate reader apparatus (model 3550-UV; BioRad Laboratories Inc.). Tumor cells were suspended in the culture medium containing various concentrations of the purified IgG, and seeded into 24-well collagen-coated plates (Asahi Techno Glass, Tokyo, Japan) at $2 \times 10^{5}$ cells/well. After 48 hours' incubation, the medium was removed by aspiration. Adherent cells were washed with PBS and collected by trypsin treatment. The number of viable cells among the adherent cells, which were not stained with Trypan Blue, was counted.

Immunofluorescence microscopy. Frozen sections of the tumor tissue were prepared and fixed with acetone at room temperature for 10 minutes. After washing with PBS, the sections were immersed in $10 \%$ normal goat serum in PBS at room temperature for 20 minutes. Staining was performed with PE-conjugated rat anti-mouse CD45R (PharMingen) or FITC-conjugated rat anti-mouse Ig polyclonal antibody (PharMingen). The sections were then washed with PBS and examined under a fluorescence microscope.

Statistics. One-way ANOVA was used to test for overall differences among the groups, followed by Tukey's honestly significant difference adjustment for multiple comparisons by use of StatMateIII (ATMS Co., Tokyo, Japan). Unpaired Student's $t$ test was used for comparison of means in two groups. Differences were considered to be significant at a $P$ value less than 0.05 . Pearson correlation was performed to determine the association using StatMateIII.
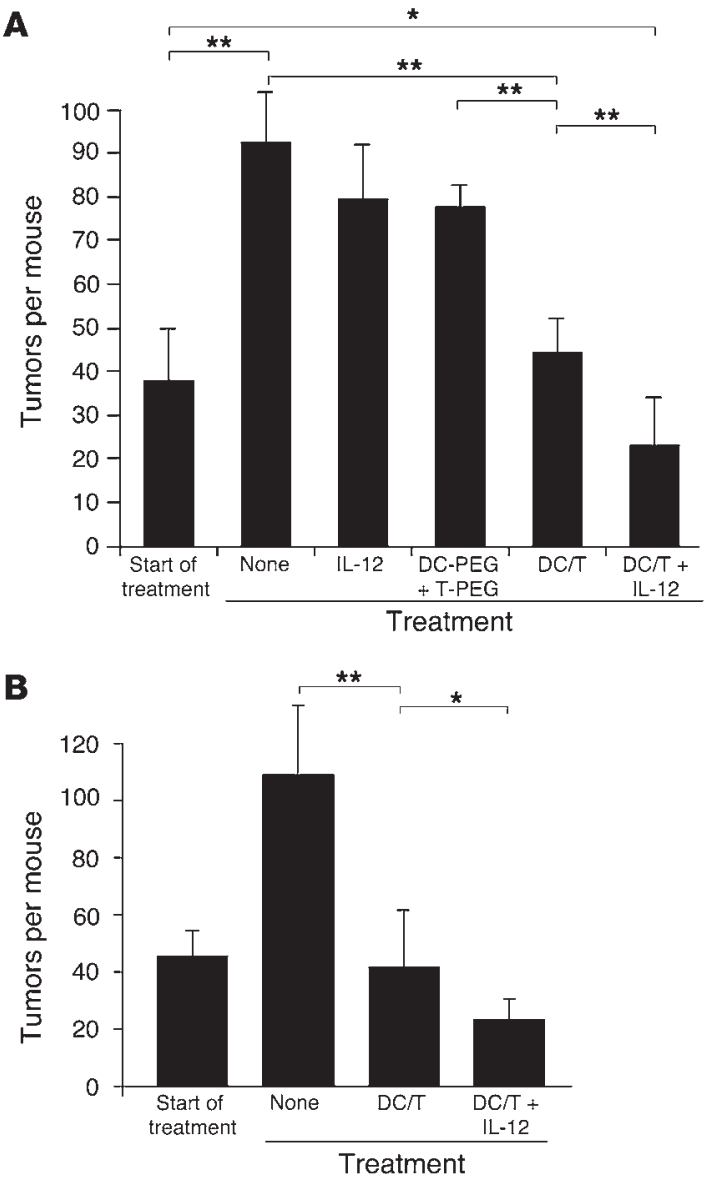


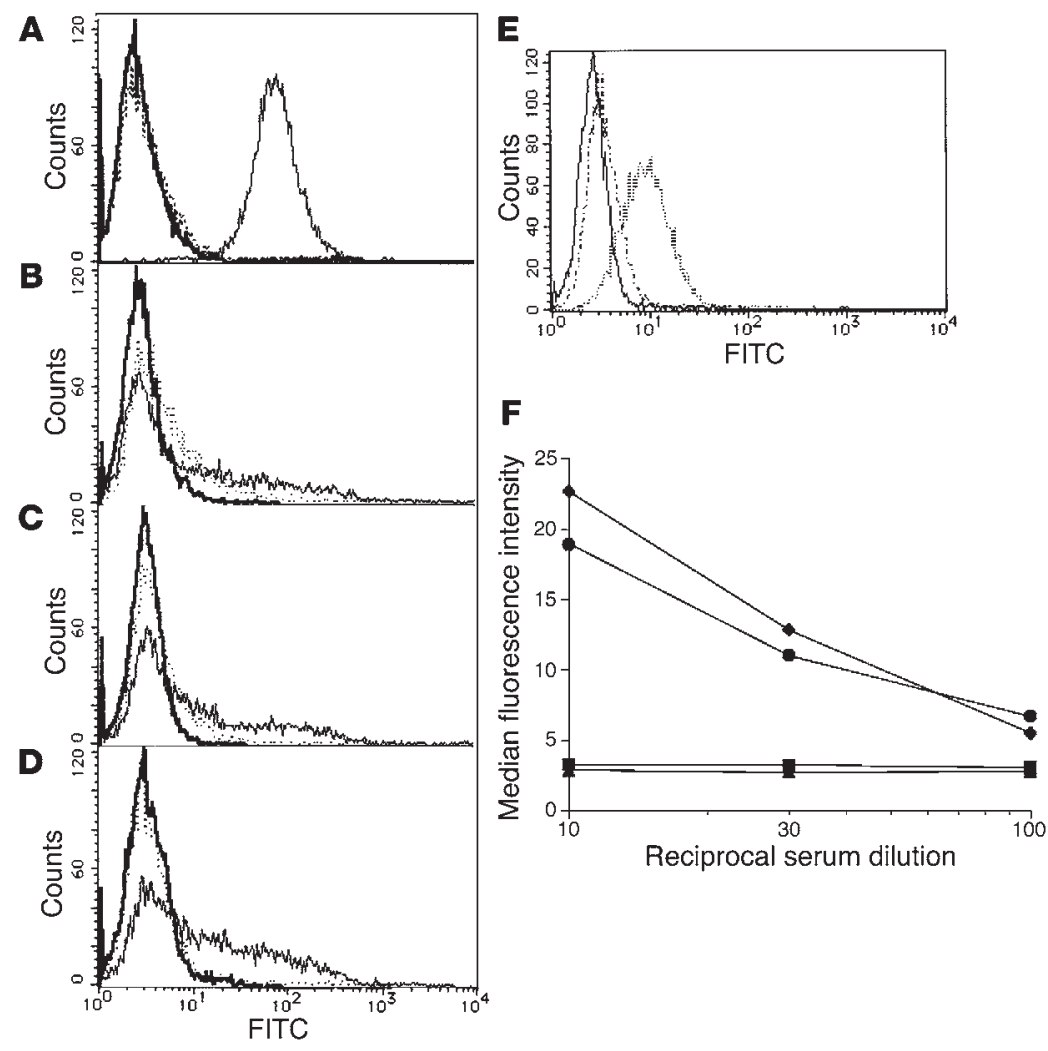

Figure 4

Reactivity of serum with tumor T cells. (A-D) Reactivity of serum from mouse treated with $\mathrm{DC} / \mathrm{T}+\mathrm{IL}-12$ against the cells derived from various carcinoma cell lines. Tumor $\mathrm{T}$ cells and other irrelevant tumor cells $\left(2 \times 10^{5}\right)$ were incubated with $50 \mu \mathrm{l}$ of the serum at $4^{\circ} \mathrm{C}$ for 30 minutes, washed extensively, and then incubated with $2 \mu \mathrm{l}$ of FITC-conjugated rat anti-mouse Ig antibody. Fluorescence histograms shown by the cells were obtained with FACS: (A) tumor T; (B) MC38 colon carcinoma; (C) B16 melanoma; (D) Hepa1-6 hepatocellular carcinoma. Thick line, negative control; dotted line, serum from untreated mouse; thin line, serum from mouse treated with $D C / T+I L-12$. (E) Decrease of serum reactivity by incubation with tumor $\mathrm{T}$ cells. Serum from a mouse treated with $\mathrm{DC} / \mathrm{T}+\mathrm{IL}-12$ was diluted 100 -fold with PBS, incubated with tumor T cells $\left(2 \times 10^{5}\right)$ at $4^{\circ} \mathrm{C}$ for 1 hour and centrifuged. Tumor T cells were incubated with $50 \mu$ of the supernatant (dashed line), 100-fold diluted serum (dotted line), or untreated mouse serum (thick line) at $4^{\circ} \mathrm{C}$ for 30 minutes, washed extensively, incubated with $2 \mu$ of FITC-conjugated rat anti-mouse Ig antibody, and submitted for flow-cytometric analysis using FACS. Three independent experiments were performed with similar results. A typical experiment is shown. (F) Serum dilution and reactivity with tumor T cells. Tumor T cells $\left(2 \times 10^{5}\right)$ were incubated with $50 \mu \mathrm{l}$ of the diluted serum at $4^{\circ} \mathrm{C}$ for 30 minutes, washed extensively, and then incubated with $2 \mu \mathrm{l}$ of FITC-conjugated rat anti-mouse Ig antibody. Fluorescence histograms shown by the cells were obtained using FACS, and the median fluorescence intensity was measured. All determinations were carried out in triplicate. Squares and triangles, sera from untreated mice; diamonds and circles, sera from mice treated with $\mathrm{DC} / \mathrm{T}+\mathrm{IL}-12$.

\section{Results}

Generation of DC/Ts. In the mixture of DCs and tumor T cells, $11.3 \%$ of the cells were stained with both PKH26GL and FITCconjugated anti-CD80 (Figure 1C), whereas $41.9 \%$ of PEG-treated DCs and tumor T cells were stained with both of them (Figure 1D). Flow-cytometric analysis showed that overnight incubation of PEG-treated DCs and tumor cells reduced the number of free tumor cells. We attribute this reduction in free tumor cells to their attachment to the culture plate. Double-stained cells that were considered to be DC/Ts occurred more frequently among the PEG- treated mixture of DCs and tumor T cells than in the mixture of DCs and tumor T cells. Under a fluorescence microscope, almost all DCs contained red-fluorescent tumor cells (Figure $1 \mathrm{H}$ ), whereas few DCs not treated with PEG contained tumor cells and some DCs contained fragments of tumor cells (Figure 1G). The phenotypes of DCs and DC/ Ts were compared (Figure 1, I-L). The expression of $\mathrm{H}-2 \mathrm{~K}^{\mathrm{b}}$, CD80, and CD86 did not vary between them. By contrast, expression of $\mathrm{I}^{\mathrm{b}} \mathrm{A}^{\mathrm{b}}$ in DC/Ts appeared to be slightly augmented as compared with that in DCs.

To assess the effect of PEG treatment on the maturation of DCs induced by LPS, we compared secretions of IL-12, IL-6, and IL-10 by DCs and DC/Ts in vitro. No significant secretions of IL-12, IL-6, and IL-10 were observed without the culture with LPS. The culture with LPS gave rise to the production of IL-12 and IL-6. However, IL-12 produced by DC/Ts was one-third of that produced by DCs $(17.8 \pm 6.8 \mathrm{ng} / \mathrm{ml}$, mean $\pm \mathrm{SD}$, $n=3$, vs. $5.9 \pm 0.6 \mathrm{ng} / \mathrm{ml}, n=3 ; P<0.05)$. The amount of IL- 6 produced by DC/Ts was less than that secreted by DCs $(29.7 \pm 4.5 \mathrm{ng} / \mathrm{ml}, n=3$, vs. $21.5 \pm 2.6 \mathrm{ng} / \mathrm{ml}, n=3)$. However, the difference was not statistically significant. No detectable amount of IL-10 was produced by DCs and DC/Ts cultured with LPS.

Prevention of tumor development by vaccination with DC/Ts in APC1309 mice and $\mathrm{APC}^{\mathrm{Min}-/+}$ mice. Fewer tumors developed in the small intestines of mice treated with DC/Ts than in untreated mice (Figure 2). Treatment with DC/T + IL-12 further inhibited tumor development.

Tumors had already developed in the gastrointestinal tracts (esophagus to rectum) of APC1309 mice when DC/T vaccination was started at 6 weeks of age (Figure $3 \mathrm{~A}$ ). At that time, each mouse had $38 \pm 12$ tumors (mean \pm SD). By 10 weeks, the number of tumors per untreated mouse had increased to $93 \pm 11$. In contrast, the number of tumors in mice treated with DC/Ts had not increased as compared with that found at the start of treatment, indicating that immunization inhibited tumor development. Notably, treatment with DC/T + IL-12 was significantly more effective in suppressing tumor development than $\mathrm{DC} / \mathrm{T}$ vaccination alone. In addition, the number of tumors in mice treated with $\mathrm{DC} / \mathrm{T}$ + IL-12 was significantly less at 10 weeks of age than at 6 weeks of age $(P<0.05)$, indicating that the tumor regressed with this treatment. In mice given DCs and tumor T cells that had each been treated separately with PEG the tumor number at 10 weeks of age did not differ significantly from that in untreated mice of the same age. In mice given a mixture of DCs and tumor T cells that had not been treated with PEG, the mean number of tumors at 10 weeks of age $(77 \pm 15, n=3)$ did not differ significantly from that in untreated mice $(93 \pm 11, n=10)$. Treatment with IL-12 alone had no significant effect. Importantly, mice treated with DC/T + IL-12 survived longer (156.8 \pm 19.1 days, $n=5)$ than did untreated mice (109.2 \pm 15.1 days, $n=5, P<0.005)$. 

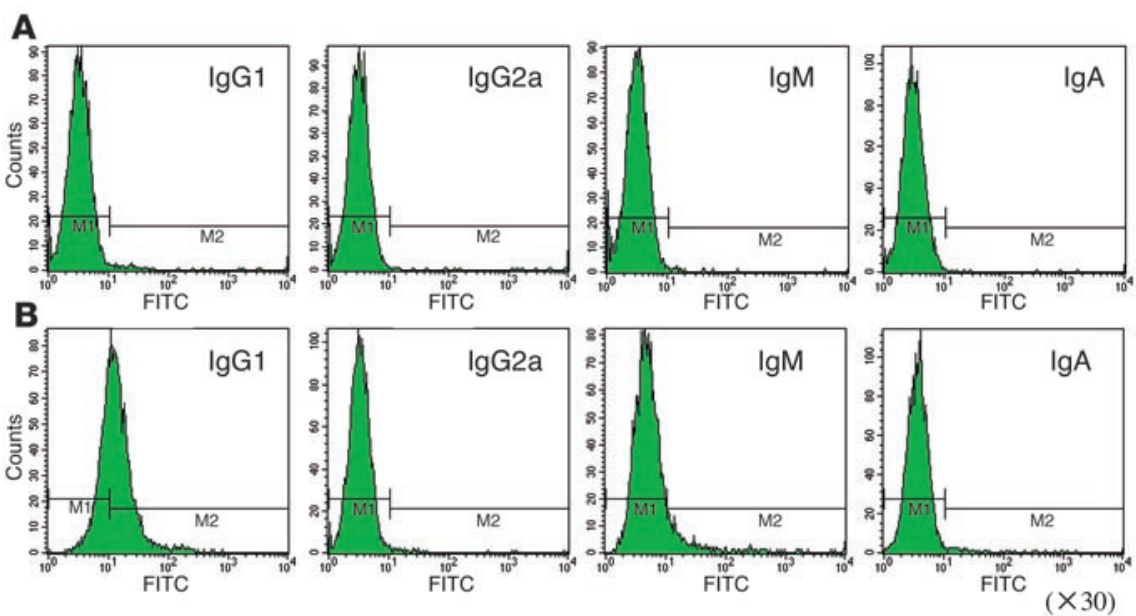

\section{Figure 5}

Analysis of Ig subclass of antibody to tumor $T$ cells. Tumor T cells were incubated, first with 30 -fold diluted sera from mice treated with $\mathrm{DC} / \mathrm{T}$ + IL-12 as described in the legend for Figure 4, and then with rat anti-mouse antibody specific for IgG1, IgG2a, IgM, or IgA as described in the text. (A) Serum from untreated mouse; (B) serum from mouse treated with $\mathrm{DC} / \mathrm{T}+\mathrm{IL}-12$.
We examined whether antitumor activity was also induced by treatment with DC/Ts in another FAP model, $A P C^{\mathrm{Min}-/+}$ mice (Figure $3 \mathrm{~B})$. Development of tumors was suppressed by treatment with DC/Ts, as it had been in APC1309 mice. Treatment with $\mathrm{DC} / \mathrm{T}+\mathrm{IL}-12$ caused a further reduction in tumor development as compared with DC/T treatment alone.

Cytotoxic activity of splenocytes from mice treated with DC/Ts. Splenocytes from mice treated with DC/Ts alone and from mice treated with DC/T + IL-12 were incubated with IL-2 for 4 days and then examined for their cytotoxic activity against tumor $\mathrm{T}$ cells as described earlier. Comparison with splenocytes from untreated mice showed no significant increase in the cytotoxic activity against tumor T cells. Since tumor T cells express MHC class I molecules constitutively, CTLs specific for tumor T cells are able to recognize the tumor cells and kill them. The aforementioned findings indicate that CTLs specific for tumor $\mathrm{T}$ cells were not generated. Splenocytes from DC/T-treated and DC/T + IL-12-treated mice were incubated with irradiated tumor $\mathrm{T}$ cells or $\mathrm{DC} / \mathrm{Ts}$ in the absence of IL-2. This treatment of splenocytes also caused no significant increase in the cytotoxic activity. Moreover, pretreatment of the tumor T cells with IFN- $\gamma$ to enhance MHC class I expression and increase susceptibility to CTLs did not increase cytotoxic activity. That killing of YAC-1 cells by splenocytes was unaffected by treatment of mice with either DC/Ts alone or DC/T + IL-12 indicates that NK cell activity was not induced.

The inability of the splenocytes to kill tumor T cells may be due to their resistance to $T$ cell-mediated killing. Splenocytes from $\mathrm{BALB} / \mathrm{c}$ mice inoculated with tumor $\mathrm{T}$ cells derived from $\mathrm{C} 57 \mathrm{BL} / 6 \mathrm{~J}$

\section{Figure 6}

Relationship between the number of gastrointestinal tumors and the median fluorescence intensity shown by the tumor cells incubated with serum. Gastrointestinal tumors were counted as described in the legend for Figure 3A. The median fluorescent intensities shown by tumor cells incubated with sera and then with FITC-conjugated rat anti-mouse Ig antibody were determined as described in the legend for Figure 4. Each symbol represents the number of gastrointestinal tumors and the median fluorescence intensity for individual mice. Filled squares, untreated mice; open circles, mice treated with $\mathrm{DC} / \mathrm{T}$; filled circles, mice treated with $\mathrm{DC} / \mathrm{T}+\mathrm{IL}-12$ (correlation coefficient: -0.535 ; $P<0.05$ ). were examined at an $\mathrm{E} / \mathrm{T}$ ratio of 80:1 for their cytotoxicity against tumor T cells and MC38 cells with the same genetic background as tumor T cells. Percentage lysis of MC38 cells by splenocytes from mice that were inoculated and those that were not was $21.8 \% \pm 2.0 \%$ $(n=3)$ and $2.2 \% \pm 1.7 \%(n=3)$, respectively. Depletion of CD8 ${ }^{+} \mathrm{T}$ cells with the MACS magnetic sorting system decreased significantly the percentage lysis of MC38 cells by the splenocytes from inoculated mice to $7.3 \% \pm 0.3 \%(n=3)(P<0.001)$. Percentages of lysis of T cells by splenocytes from the inoculated and uninoculated mice were $4.4 \% \pm 0.4 \%(n=3)$ and $3.2 \% \pm 0.5 \%(n=3)$, respectively.

Induction of humoral antitumor immunity by treatment with DC/Ts. To assess the induction of antitumor antibody, tumor $\mathrm{T}$ cells were incubated with sera from APC1309 mice and then with FITC-conjugated rat anti-mouse Ig, and analyzed with FACS. The amount of Ig bound to tumor $T$ cells was estimated by determining the median fluorescence intensity. Tumor $\mathrm{T}$ cells showed higher median fluorescence intensity when incubated with sera from mice inoculated with DC/T + IL-12 than when incubated with sera from untreated mice (Figure 4, A-D). However, MC38 colon carcinoma cells, B16 melanoma cells, and Hepa1-6 hepatocellular carcinoma cells did not show increased median fluorescence intensity when incubated with sera from mice treated with DC/T + IL-12, although low serum reactivities with these cells were seen (Figure 4, A-D). Prior incubation of sera from mice treated with DC/T + IL-12 with tumor T cells decreased the median fluorescence intensity to a level comparable to that found with sera from untreated mice (Figure 4E). The median fluorescence intensities shown by tumor $\mathrm{T}$ cells on incubation with sera from mice treated with DC/T + IL-12 decreased with dilution of 


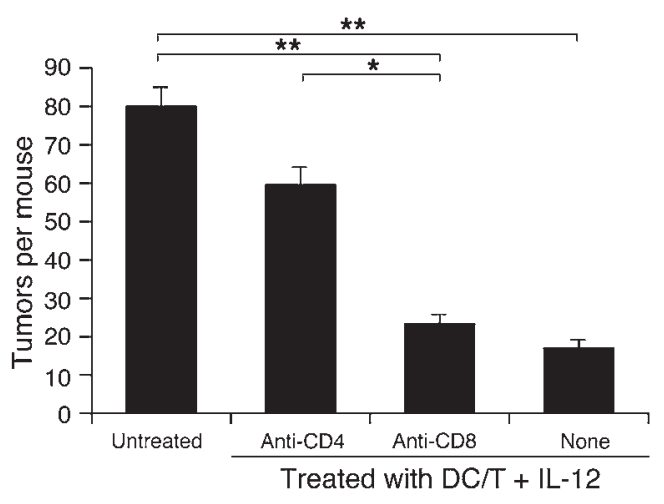

the sera (Figure 4F). Together, these findings indicate that sera from mice treated with DC + IL-12 contained antibody against tumor T cells. Subclass analysis of antibody with antibodies specific for IgG1, IgG2a, IgA, and IgM demonstrated that Ig reactive with tumor $\mathrm{T}$ cells was mainly IgG1, although small amounts of IgM antibody were detected (Figure 5). No IgG2a antibody, which reflected induction of Th1 response, was detected.

The mean median fluorescence intensity with sera from DC/Ttreated mice was significantly higher than that with sera from untreated mice (14.76 \pm 7.05 vs. $3.08 \pm 0.40 ; P<0.05)$ (Figure $6)$. Moreover, the mean median fluorescence intensity with sera from DC/T + IL-12-treated mice was greater than that obtained with sera from DC/T-treated mice (24.66 \pm 12.61 vs. $14.76 \pm 7.05$; $P<0.05)$. Importantly, there was a negative correlation between median fluorescence intensities and the numbers of tumors at 10 weeks of age in DC/T- and DC/T + IL-12-treated mice (correlation coefficient: $-0.535 ; P<0.05)$.

Effect of depletion of $\mathrm{CD}^{+}$or $\mathrm{CD} 8^{+} \mathrm{T}$ cells on the antitumor effect induced by $D C / T+I L-12$. The studies just cited showed that CTLs were not involved in the prevention of tumor development. To confirm this result, we administered anti-mouse CD4 and antimouse CD8 mAb's to mice treated with DC/T + IL-12 to deplete $\mathrm{CD}^{+}$and $\mathrm{CD}^{+} \mathrm{T}$ cells in vivo, respectively. In mice injected with anti-CD4 mAb's, the numbers of $\mathrm{CD}^{+}{ }^{+} \mathrm{T}$ cells were $43.3 \%, 42.3 \%$, and $3.0 \%$ of the baseline level on 1, 3, and 6 days, respectively, after the last injection, whereas those of $\mathrm{CD}^{+} \mathrm{T}$ cells were $73.7 \%, 59.9 \%$, and $66.0 \%$. In mice injected with anti-CD $8 \mathrm{mAb}$ 's, the numbers of $\mathrm{CD}^{+} \mathrm{T}$ cells were $25.1 \%, 22.2 \%$, and $2.7 \%$ of the baseline level on 1,3 , and 6 days, respectively, after the last injection, whereas the those of CD4 ${ }^{+} \mathrm{T}$ cells were $83.3 \%, 74.0 \%$, and $113.3 \%$. Mice given anti-CD4 antibody had significantly more tumors than those given anti-CD8 antibody $(P<0.01)$ (Figure 7$)$. Furthermore, the number of tumors in the mice given anti-CD4 antibody did not differ significantly from that in the untreated mice.

ELISPOT assay for T cells secreting IL-4 and IFN- $\gamma$. To confirm the predominance of the Th2 response in the antitumor immunity induced by DC/Ts, we performed ELISPOT assays for the frequencies of $\mathrm{CD}^{+} \mathrm{T}$ cells and $\mathrm{CD}^{+} \mathrm{T}$ cells producing IL-4 or IFN- $\gamma$ (Tables 1 and 2 ). In $\mathrm{CD}^{+} \mathrm{T}$ cells stimulated in vitro with $\mathrm{DC} / \mathrm{T}$, the frequencies of cells secreting IL-4 and IFN- $\gamma$ were higher in mice treated with DC/Ts and with DC/T + IL-12 than in untreated mice (Table 1$)$. In the treated mice, cells secreting IL-4 were more frequent than cells secreting IFN- $\gamma(P<0.001)$. In $\mathrm{CD}^{+} \mathrm{T}$ cells stimulated with tumor $\mathrm{T}$ cells, the frequency of cells secreting IFN- $\gamma$ was not increased, although that of cells secreting IL-4 was increased markedly.

\section{Figure 7}

Effect of administration of anti-CD4 mAb's or anti-CD8 mAb's on the antitumor effect induced by DC/Ts. Anti-mouse CD4 mAb's or antimouse CD8 mAb's were administered at a dose of $0.5 \mathrm{mg} / \mathrm{mouse}$ intraperitoneally, 1 day before and 2 days after each of the DC/T inoculations; these mice were treated with IL-12 and sacrificed at 10 weeks of age as described in the text. The tumors in the gastrointestinal tracts were counted as described in the legend for Figure 3. Each column represents mean \pm SD (error bar) of the number of tumors $(n=3)$. ${ }^{*} P<0.01 ;{ }^{* *} P<0.001$.

On stimulation of CD8 ${ }^{+} \mathrm{T}$ cells with DC/Ts, the frequency of cells secreting IFN- $\gamma$ was slightly higher in those from mice treated with $\mathrm{DC} / \mathrm{T}+\mathrm{IL}-12$, not mice treated with $\mathrm{DC} / \mathrm{Ts}$ alone, than in those from untreated mice (Table 2). On stimulation of $\mathrm{CD}^{+}$cells with the irradiated tumor $\mathrm{T}$ cells, however, there was no difference with respect to the frequency of $\mathrm{CD}^{+} \mathrm{T}$ cells secreting IFN- $\gamma$ between untreated and treated mice. Cytotoxic activity of serum IgG from mice treated with $D C / T+I L-12$ against tumor $T$ cells. Sera from mice treated with DC/T + IL-12 were cytotoxic in vitro against tumor T cells. To exclude involvement of complement or other cytotoxic factors in the sera, we purified IgG from sera of mice treated with DC/Ts alone or with DC/T + IL-12 and examined it for in vitro cytotoxic activity against tumor $\mathrm{T}$ cells. Tumor $\mathrm{T}$ cells were cultured for 48 hours in the medium containing various concentrations of IgG purified from sera of untreated mice, mice treated with DC/Ts alone, or mice treated with DC/T + IL-12. Phase-contrast microscopy showed that most tumor cells were detached from the plate after culture in the medium containing IgG from DC/T + IL-12-treated mice (Figure $8 \mathrm{~B}$ ), while the tumor cells remained attached to the plate after culture in the presence of the same concentration of IgG from untreated mice (Figure 8A). Since all detached cells were stained with Trypan Blue and the attached cells were not, the cells attached to the plate were counted as viable cells. IgG from DC/Ttreated mice decreased the viable cells in a dose-dependent manner, whether they were treated with IL-12 or not (Figure 9).

Ig on the surface of tumor cells in the tumor tissue of mice treated with $D C / T+I L-12$. Some $C D 4^{+} T$ cells were observed in the tumor tissue of DC/T + IL-12-treated mice but not in that of untreated mice,
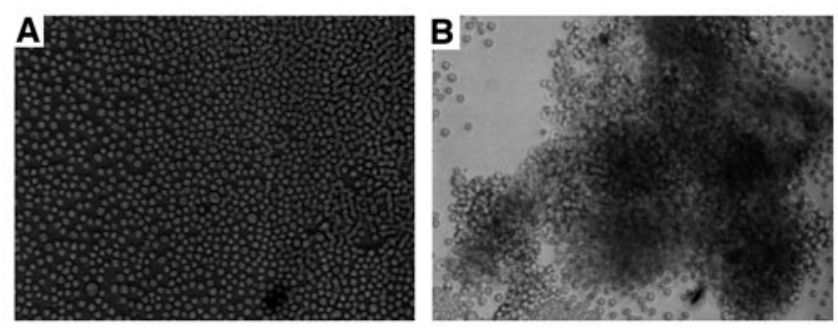

\section{Figure 8}

Phase-contrast microscopy of tumor cells cultured with IgG purified from mice treated with $\mathrm{DC} / \mathrm{T}+\mathrm{IL}-12$. Tumor $\mathrm{T}$ cells were cultured for 48 hours in the presence of $0.02 \mathrm{mg} / \mathrm{ml} \mathrm{IgG}$ purified from untreated mice (A) and mice treated with $\mathrm{DC} / \mathrm{T}+\mathrm{IL}-12$ (B). Many tumor cells were detached from the culture plate in the presence of $\mathrm{IgG}$ from mice treated with $\mathrm{DC} / \mathrm{T}+\mathrm{IL}-12$. 


\section{Table 1}

Frequencies of cells secreting IL-4 and IFN- $\gamma$ in CD4+ T cells stimulated with $\mathrm{DC} / \mathrm{Ts}$ or irradiated tumor T cells $(\mathrm{T})$

\begin{tabular}{|c|c|c|c|c|}
\hline \multirow[t]{2}{*}{ Mice } & \multicolumn{2}{|c|}{ DC/T-stimulated } & \multicolumn{2}{|c|}{ T-stimulated } \\
\hline & IL-4A & IFN- $\gamma^{B}$ & IL-4A & IFN- $\gamma^{B}$ \\
\hline Untreated & $9.3 \pm 1.1$ & $4.3 \pm 2.5$ & $2.5 \pm 0.3$ & $7.0 \pm 0$ \\
\hline Treated with DC/Ts & $33.9 \pm 2.3^{c}$ & $14.6 \pm 2.1^{D}$ & $12.5 \pm 1.3^{\mathrm{C}}$ & $9.7 \pm 2.1$ \\
\hline Treated with DC/T + IL-12 & $31.2 \pm 1.6^{C}$ & $13.0 \pm 3.0^{\mathrm{E}}$ & $18.9 \pm 1.3^{\mathrm{C}, \mathrm{F}}$ & $6.7 \pm 1.2$ \\
\hline
\end{tabular}

Note: $\mathrm{CD} 4^{+} \mathrm{T}$ cell-enriched fractions were prepared from splenocytes of untreated $A P C 1309$ mice and those treated with $\mathrm{DC} / \mathrm{Ts}$ or $\mathrm{DC} / \mathrm{T}+\mathrm{IL}-12$ as described in the text. After stimulation of these fractions with $\mathrm{DC} / \mathrm{Ts}$ or irradiated tumor $\mathrm{T}$ cells, frequencies of cells secreting IL-4 or IFN- $\gamma$ were determined by ELISPOT assays as described in the text and expressed as number of spots per $10^{4} \mathrm{CD} 4^{+} \mathrm{T}$ cells. Values represent means $\pm \mathrm{SD}(n=3)$. AFrequency of cells secreting IL-4. BFrequency of cells secreting IFN- $\gamma$. ${ }^{C} P<0.001$ vs. untreated; $D P<0.01$ vs. untreated; $\mathrm{E} P<0.05$ vs. untreated; $\mathrm{F} P<0.01$ vs. $\mathrm{DC} / \mathrm{T}$.

whereas very few $\mathrm{CD} 8^{+} \mathrm{T}$ cells were seen in the tumor tissue of either DC/T + IL-12-treated mice or untreated mice (data not shown).

Numerous enlarged lymphoid follicles were found on the mucosal surface of the intestines of mice treated with DC/Ts alone and those treated with DC/T + IL-12, but not in the intestines of untreated mice. Immunofluorescence microscopy of the lymphoid follicles demonstrated a predominant population of $\mathrm{CD} 45 \mathrm{R}^{+}$and $\mathrm{Ig}^{+}$cells. Ig was bound to the tumor cell surface in the tumor tissue of a mouse treated with DC/T + IL-12 (Figure 10, arrows).

\section{Discussion}

The ability of DCs loaded with TAAs to prime naive T cells capable of recognizing and killing tumor cells in an antigen-specific manner has been demonstrated in various animal models (34). Given the genomic instability associated with development of tumors, numerous TAAs are potential targets for antitumor immunity. However, TAAs have been identified in few tumors. Approaches to loading DCs with unidentified TAAs include pulsing DCs with tumor cell lysates, transfection of DCs with tumor cell RNA, and fusion of DCs with tumor cells (26-28). There are two methods for generation of fusion cells: PEG treatment and electrofusion (35). Fusion efficacy of PEG treatment and vaccine potency of fusion cells in induction of antitumor immunity is similar to those of electrofusion (35). In the present study, we used PEG treatment to load DCs with tumor cells. Fusion cells express both tumor antigens and the DC-derived molecules needed to prime an immune response (36).

To assess generation of DC/Ts, a mixture of DCs and tumor $\mathrm{T}$ cells that had been stained with FITC-conjugated anti-CD80 and PKH26GL respectively, were treated with PEG or not so treated, cultured overnight, and examined by two-color FACS analysis and fluorescence microscopy. FACS analysis showed that PEG treatment of a mixture of DCs and tumor cells increased the frequency of cells stained with both FITC-conjugated anti-CD80 and PKH26GL which were considered DC/Ts. With fluorescence microscopy, almost all cells collected after treatment with PEG were DC/Ts that contained red-fluorescent tumor cells, a finding suggesting that DCs phagocytose tumor cells rather than fuse with them and that DCs are loaded with tumor cells by phagocytosis. The discrepancy of DC/T frequencies estimated by FACS analysis and fluorescence microscopy may be due to FACS analysis not being able to detect all DCs that phagocytosed the tumor cells. The pathways through which DCs take up antigens and present them to T lymphocytes include receptor-mediated endocytosis, macropinocytosis, and phagocytosis (37). Physiologically, phagocytosis is probably a major route for the uptake of antigens and presentation of the antigen-derived peptides on MHC class I as well as MHC class II molecules (cross presentation) (37). The frequency of DCs containing tumor cells was higher in a PEG-treated mixture of DCs and tumor T cells than in a similar mixture not treated with PEG. This finding shows that treatment of DCs and tumor cells with PEG causes efficient internalization of tumor cell by DCs. The present study showed that internalization by phagocytosis of whole tumor cells into DCs could induce the antitumor immunity. However, PEG-treated tumor $\mathrm{T}$ cells might have been phagocytosed by the recipient APCs to induce the antitumor effect. This possibility was excluded by the finding that the administration of PEGtreated tumor $\mathrm{T}$ cells did not induce the antitumor effect.

In the present study, $A P C 1309$ and $A P C^{\mathrm{Min}-/^{+}}$mice, in which many gastrointestinal tumors developed spontaneously, were immunized with DC/Ts. Our results demonstrate that the treatment with DC/Ts can prevent further development of gastrointestinal tumors in both mouse models. Although DCs were loaded with tumor cells derived from APC1309 mice and the mutation site of the APC gene differed between $A P C 1309$ and $A P C^{\text {Min-/+ }}$ mice, tumor development in $A P C^{\mathrm{Min}-/+}$ mice was also inhibited by inoculation with DC/Ts. This result suggests that tumor cells generated by mutation of the APC gene express common antigen despite having different sites of gene mutation.

Our present study found that APC1309 mice treated with DC/T + IL-12 had fewer tumors at 10 weeks of age than did untreated mice at 6 weeks of age, a finding that suggests that this combined treatment causes preexisting tumors to regress. Although administration of IL-12 alone reportedly induced antitumor activity in some mouse tumor models $(38,39)$, we found no evidence that IL-12 alone had any preventive effect on the spontaneous development of tumors in APC1309 mice.

In the present study, DC/T inoculation alone or with IL-12 induced no detectable in vitro cell-mediated cytotoxic activity against tumor cells. However, as shown later, this was due to the intrinsic resistance of tumor $\mathrm{T}$ cells to cytotoxicity. Splenocytes from $\mathrm{BALB} / \mathrm{c}$ mice inoculated with tumor $\mathrm{T}$ cells did not induce

\section{Table 2}

Frequencies of cells secreting IL-4 and IFN- $\gamma$ in $C D 8^{+} T$ cells stimulated with $\mathrm{DC} / \mathrm{Ts}$ or irradiated tumor $\mathrm{T}$ cells $(\mathrm{T})$

\begin{tabular}{|c|c|c|c|c|}
\hline \multirow[b]{2}{*}{ Mice } & \multicolumn{2}{|c|}{ DC/T-stimulated } & \multicolumn{2}{|c|}{ T-stimulated } \\
\hline & IL-4A & IFN- $\gamma^{B}$ & IL-4A & IFN- $\gamma^{B}$ \\
\hline Untreated & $2.3 \pm 0.5$ & $7.7 \pm 1.7$ & $0.4 \pm 0.2$ & $1.3 \pm 0.3$ \\
\hline Treated with DC/Ts & $2.6 \pm 0.5$ & $9.1 \pm 0.5$ & $0.3 \pm 0.2$ & $1.3 \pm 0.2$ \\
\hline Treated with $\mathrm{DC} / \mathrm{T}+\mathrm{IL}-12$ & $3.3 \pm 0.5$ & $10.7 \pm 0.5^{c}$ & $0.5 \pm 0.1$ & $1.2 \pm 0.2$ \\
\hline
\end{tabular}

Note: Frequencies of cells secreting IL-4 and IFN- $\gamma$ in $\mathrm{CD}^{+} \mathrm{T}$ cells stimulated with DC/Ts or irradiated tumor T cells were determined by ELISPOT assays as described in the note for Table 1 and expressed as the number of spots per $10^{4}$ CD8 + T cells. Values represent means $\pm \operatorname{SD}(n=3)$. AFrequency of cells secreting IL-4. BFrequency of cells secreting IFN- $\gamma$. ${ }^{C} P<0.05$ vs. untreated. 


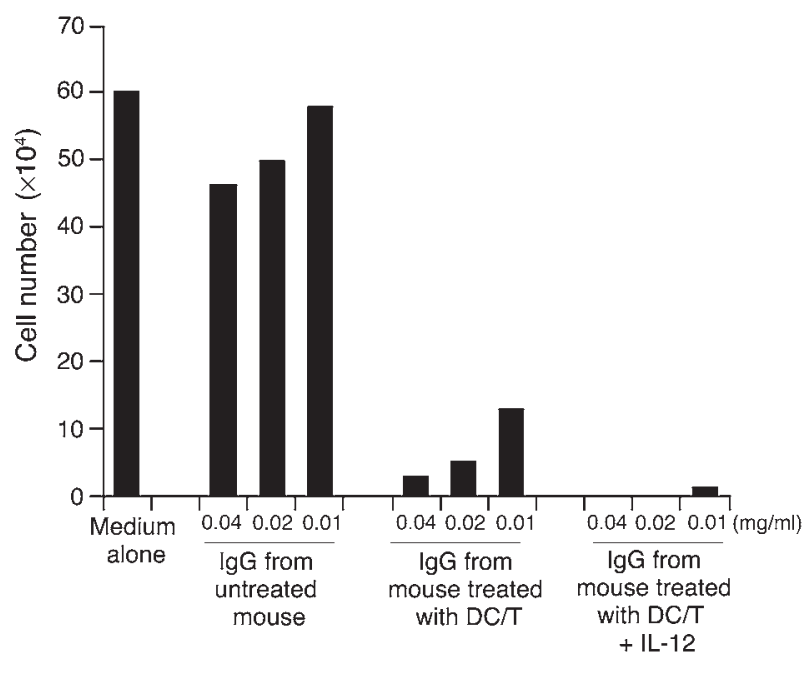

significant lysis of tumor T cells, whereas they exhibited substantial lytic activity against MC38 cells with the same genetic background as tumor T cells. The significant decrease of lysis of MC38 by in vitro $\mathrm{CD}^{+} \mathrm{T}$ cell depletion indicates that the cytotoxic activity by splenocytes was mainly mediated by $\mathrm{CD}^{+} \mathrm{T}$ cells. These findings suggest that tumor $\mathrm{T}$ cells were resistant to $\mathrm{T}$ cell-mediated lysis. Because CTL assays could not be used as an indicator of elicited $\mathrm{CD}^{+} \mathrm{T}$ cell responses, IFN- $\gamma$ ELISPOT assays of $\mathrm{CD}^{+} \mathrm{T}$ cells were performed instead. The stimulation of $\mathrm{CD}^{+} \mathrm{T}$ cells of the treated mice with tumor T cells or DC/Ts caused no substantial increase in the frequency of those secreting IFN- $\gamma$ in ELISPOT assays as compared with untreated mice. Furthermore, stimulation of $\mathrm{CD}^{+} \mathrm{T}$ cells with tumor T cells did not increase the production of IFN- $\gamma$ in the treated and untreated mice (data not shown). In mice treated with DC/Ts and those treated with DC/T + IL-12, the predominance of $\mathrm{CD}^{+} \mathrm{T}$ cells secreting IL-4 over those secreting IFN- $\gamma$ on the stimulation with DC/Ts favored the induction of a Th2 response. Together, these findings suggested that the Th2 response predominated in mice inoculated with DC/Ts. Furthermore, we found no evidence that $\mathrm{CD}^{+} \mathrm{T}$ cells infiltrated tumor tissue, although $\mathrm{CD}^{+}$ $\mathrm{T}$ cells infiltrated to a modest degree (data not shown). The results demonstrate that $\mathrm{DC} / \mathrm{T}$ vaccination induces an antibody response against tumor $\mathrm{T}$ cells. The negative correlation of antibody activity with the number of tumors suggests that the prevention and regression of tumors were mediated by the antibody in vaccinated mice. $\mathrm{A} \mathrm{CD}^{+} \mathrm{T}$ cell-depletion study also excluded a possible role of CTL-mediated cytotoxicity in DC/T-induced antitumor immunity. The depletion of $\mathrm{CD}^{+} \mathrm{T}$ cells by administration of anti-CD $8 \mathrm{mAb}$ 's did not decrease the antitumor effect induced by treatment with $\mathrm{DC} / \mathrm{T}+\mathrm{IL}-12$, whereas the depletion of $\mathrm{CD} 4^{+} \mathrm{T}$ cells by administration of anti-CD4 mAb's abolished the antitumor effect, indicating the critical role of $\mathrm{CD} 4^{+} \mathrm{T}$ cells in the induction of antitumor effect. The failure of anti-CD $8 \mathrm{mAb}$ 's administration to diminish the antitumor effect might be due to insufficient depletion of $\mathrm{CD}^{+} \mathrm{T}$ cells. A previous study showed that the number of DCs and DC/Ts in draining lymph nodes peaked 24-48 hours after injection and then gradually decreased after 96 hours (40). In our experimental design, $\mathrm{CD}^{+} \mathrm{T}$ cells were predicted to decrease to $25 \%, 20 \%$, and about $3 \%$ of the baseline level at 3, 5, and 8 days, respectively, after the inoculation of DC/Ts. Thus it seems reasonable to assume that $\mathrm{CD}^{+} \mathrm{T}$ cells were markedly reduced during their priming phase and that

\section{Figure 9}

Cytotoxicity shown by $\lg G$ purified from sera of mice treated with $\mathrm{DC} / \mathrm{Ts}$ or $\mathrm{DC} / \mathrm{T}+\mathrm{IL}-12$. Tumor T cells $\left(2 \times 10^{5}\right.$ cells $)$ were cultured for 48 hours in the medium containing various concentrations of IgG purified from sera of mice untreated or treated with DC/Ts or DC/T + IL-12. After removal of the medium, the cells that adhered to the plate were detached by trypsinization and counted. All determinations were carried out in triplicate. Three independent experiments were performed with similar results. A typical experiment is shown.

primed $\mathrm{CD}^{+} \mathrm{T}$ cells were depleted. Despite this probability, the antitumor immunity was not inhibited, ruling out involvement of CTLs in the antitumor immunity.

IgG from mice treated with DC/Ts alone or with DC/Ts + IL-12 killed tumor cells in vitro without addition of complement, indicating that the antibody directed against tumor $\mathrm{T}$ cells was itself cytotoxic. Since the antibody reacted with intact tumor $\mathrm{T}$ cells, the target antigen is apparently on the surface, allowing the circulating antibody to react with the antigen. A cytotoxic $\mathrm{mAb}$ that binds to ErbB-2, a member of the EGFR family, and induced apoptosis has been reported (41). The antibody produced in the mice inoculated with DC/Ts might be directed against growth factor receptor-related molecules.

The foregoing findings differ from those of previous studies showing that vaccination with DCs fused with tumor cells by PEG induced CTLs against tumor cells $(36,40,42-44)$. In the present study, DC/T vaccination with or without IL-12 treatment induced production of IgG1 class antibodies, which are characteristic of the Th2 response. Furthermore, the antibody activity was higher in mice treated with DC/T + IL-12 than in those treated with DC/Ts alone. IL-12 generally induces a Th1 response including enhancement of cell-mediated immunity and production of IgG2a class antibodies $(45,46)$. However, IL-12 stimulated post-switched cells, including cells producing IgG1, to secrete increased amounts of antibody (47). We have no definitive explanation for the induction of the Th2 response, but not the Th1 response, in the present study. Failure to induce CTL-mediated cytotoxicity may be due to a defect of maturation capacity of DCs treated with PEG. Comparison of phenotypic expressions of DCs and DC/Ts showed that there was no phenotypic difference except slightly increased expression of I-A $\mathrm{A}^{\mathrm{b}}$ in DC/Ts as compared with DCs. Production of IL- 12 by DC/Ts
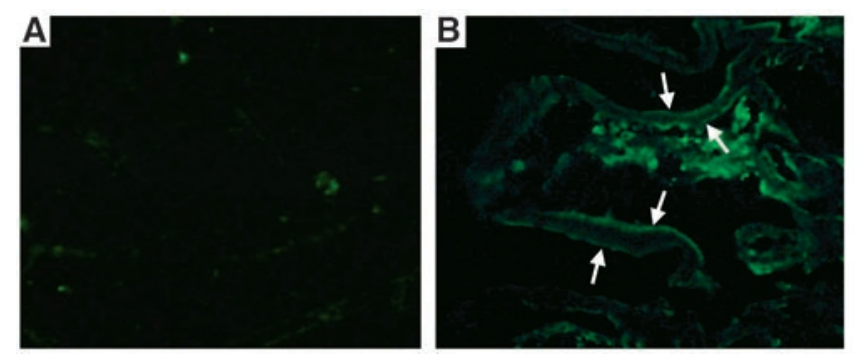

\section{Figure 10}

Immunofluorescence microscopy of gastrointestinal tumors. Tumors of APC1309 mice were analyzed with FITC-conjugated rat anti-mouse Ig antibody. Note the abundant Ig on tumor cells in the tumor tissue of a mouse treated with $\mathrm{DC} / \mathrm{T}+\mathrm{IL}-12$. Original magnification: $\times 40$. (A) Tumor tissue of untreated mouse; (B) tumor tissue of mouse treated with $\mathrm{DC} / \mathrm{T}+\mathrm{IL}-12$. Arrows indicate Ig bound to tumor cells under the immunofluorescence microscope. 
was diminished as compared with DCs, a situation that might also favor a Th2 response. Thus the inhibition of DC maturation by PEG treatment was ruled out as a cause of the failure to induce CTLmediated cytotoxicity. One of the explanations may be that tumor cells were loaded on DCs mainly by phagocytosis. We emphasize that in those studies inoculation of DCs loaded with tumor antigens inhibited or prevented the growth of transplanted tumor cells, not of tumors that developed spontaneously. To our knowledge, the present study is the first to demonstrate that a DC-based vaccine prevents the spontaneous development of tumor in animal models. In HER-2/neu transgenic mice, Nanni et al. showed the prevention of spontaneous mammary carcinogenesis through vaccination with allogeneic tumor cells along with systemic administration of IL-12 (48). This strategy did not induce CTL-mediated cytotoxicity against tumor cells, but the antibody subsequently generated to p185 neu induced complement-dependent lysis of syngeneic tumor cells . In that study, however, they suggested that, in the antitumor effect, IL-12-induced production of IFN- $\gamma$ by $\mathrm{CD}^{+} \mathrm{T}$ cells played a central role by modulating the behavior of tumor cells. In our present study, ELISPOT assays did not provide us with evidence that IL-12 increased the production of IFN- $\gamma$ by CD8 ${ }^{+} \mathrm{T}$ cells.

Our study demonstrates that $\mathrm{DC} / \mathrm{T}$ vaccination inhibits the spontaneous development of tumor in genetic tumor models, indicating that this vaccination strategy may be also effective for preventing tumor development in FAP patients with APC gene muta- tions. The current treatment of choice in patients with colorectal cancers is surgical resection, which can miss small tumors. However, surgical resection does provide cancer specimens large enough to prepare tumor cells for generation of DC/Ts. Immunization with $\mathrm{DC} / \mathrm{Ts}$ could then be used to prevent tumor recurrence. In our preliminary study, subcutaneous administration of DC/Ts was as effective as intravenous administration for inducing antitumor immunity. The antibody detected in DC/T-treated mice might be used to cause preexisting tumor to regress and prevent additional tumors from developing. Our laboratory continues to produce $\mathrm{mAb}$ 's reactive with tumor cells and to identify target antigens.

\section{Acknowledgments}

This work was supported by a grant-in-aid of the Bio-Venture Research Fund Project Aid from the Ministry of Education, Science and Culture of Japan. We thank Hisako Arai (Institute of DNA Medicine, Jikei University School of Medicine) for excellent technical assistance in immunofluorescence studies.

Received for publication November 6, 2002, and accepted in revised form February 25, 2004.

Address correspondence to: Toshio Iinuma, 3-25-8, Nishi-shimbashi, Minato-ku, Tokyo 105-8461, Japan. Phone: 81-3-3433-1111; Fax: 81-3-3433-1230; E-mail: t.iinuma@jikei.ac.jp.
1. Boyle, P., and Langman, J.S. 2000. ABC of colorectal cancer. Epidemiology. Br. Med. J. 321:805-808.

2. Boland, C.R. 1995. Malignant tumors of the colon. In Textbook of gastroenterology, $2^{\text {nd }}$ Edition. T. Yamada, editor. Lippincott Williams \& Wilkins Publishers, Philadelphia. 1967-2026.

3. Kinzler, K.W., et al. 1991. Identification of FAP locus genes from chromosome 5q21. Science. 253:661-665.

4. Lynch, H.T., and Smyrk, T. 1996. Hereditary nonpolyposis colorectal cancer (Lynch syndrome). An updated review. Cancer. 78:1149-1167.

5. Peltomaki, P., and Vasen, H.F.A. 1997. Mutations predisposing to hereditary nonpolyposis colorectal cancer: database and results of a collaborative study. Gastroenterology. 113:1146-1158.

6. Fodde, R. 2002. The APC gene in colorecta cancer. Eur. J. Cancer. 38:867-871.

7. Nakamura, Y. 1997. Cleaning up on $\beta$-catenin. News \& Views. Nat. Med. 3:499-500.

8. Hawk, E., Lubet, R., and Limburg, P. 1999. Chemoprevention in hereditary colorectal cancer syndromes. Cancer. 86:2551-2563.

9. Quesada, C.F., et al. 1998. Piroxicam and Acarbose as chemopreventive agents for spontaneous intestinal adenomas in APC gene 1309 knockout mice. Jpn. J. Cancer Res. 89:392-396.

10. Janne, P.A., and Mayer, R.J. 2000. Chemoprevention of colorectal cancer. N. Engl. J. Med. 342:1960-1968.

11. Bus, P.J., Verspaget, H.W., Lamers, C.B.H.W., and Griffioen, G. 2000. Chemoprevention of colorectal cancer by non-steroidal anti-inflammatory drugs. Scand. J. Gastroenterology Suppl. 232:101-104.

12. Rosenburg, S.A. 1997. Cancer vaccine based on the identification of genes encoding cancer regression antigens. Immunol. Today. 18:175-182.

13. Celluzzi, C.M., Mayordomo, J.I., Storkus, W.J., Lotze, M.T., and Falo, L.D., Jr. 1996. Peptide-pulsed dendritic cells induce antigen-specific CTL-mediated protective tumor immunity. J. Exp. Med. 183:283-287.

14. Zivogel, L., et al. 1996. Therapy of murine tumors with tumor peptide-pulsed dendritic cells: dependence on T cells, B7 costimulation, and T helper cell-associated cytokines. J. Exp. Med. 183:87-97.

15. Marincola, F.M., Jaffee, E.M., Micklin, D.J., and Ferrone, S. 2000. Escape of human solid tumors from T-cell recognition: molecular mechanisms and functional significance. Adv. Immunol. 74:181-273.

16. Toes, R.M., et al. 1997. Activation of frustration of anti-tumor responses by T-cell-based immune modulation. Semin. Immunol. 9:323-327.

17. Fong, L., and Engleman, E.G. 2000. Dendritic cells in cancer immunotherapy. Ann. Rev. Immunol. 18:245-273.

18. Bauchereau, B., and Steinman, R.M. 1998 Dendritic cells and the control of immunity. Nature. 392:245-252.

19. Ingulli, E., Mondino, A., Khoruts, A., and Jenkins, M.K. 1997. In vivo detection of dendritic cell antigen presentation to CD4 ${ }^{+} \mathrm{T}$ cells. J. Exp. Med. 185:2133-2141.

20. Steinman, R.M. 1991. The dendritic cell system and its role in immunogenicity. Annu. Rev. Immunol. 9:271-296.

21. James, W.Y., and Inaba, K. 1996. Dendritic cells as adjuvants for class I major histocompatibility complex-restricted antitumor immunity. J. Exp. Med. 183:7-11.

22. Mayorodomo, J.I., et al. 1995. Bone marrowderived dendritic cells pulsed with synthetic tumor peptides elicit protective and therapeutic antitumor immunity. Nat. Med. 1:1297-1302.

23. Butterfield, L.H., et al. 1998. Generation of melanoma-specific cytotoxic $\mathrm{T}$ lymphocytes by dendritic cells transduced with a MART-1 adenovirus. J. Immunol. 161:5607-5613.

24. Condon, C., Watkins, S.C., Celluzzi, C.M., Thompson, K., and Falo, D.J., Jr. 1996. DNA-based immunization by in vivo transfection of dendritic cells. Nat. Med. 2:1122-1128.

25. Koido, S., Kashiwaba, M., Chen, D., Gendler, S., and Kufe, D. 2000. Induction of antitumor immunity by vaccination of dendritic cells transfected with MUC1 RNA. J. Immunol. 165:5713-5719.

26. Nair, S.K., Snyder, D., Rouse, B.T., and Gilboa, E. 1997. Regression of tumors in mice vaccinated with professional antigen-presenting cells pulsed with tumor extracts. Int. J. Cancer. 70:706-715.

27. Boczkowski, D., Nair, S.K., Nam, J.H., Lyerly, H.K., and Gilboa, E. 2000. Induction of tumor immunity and cytotoxic $T$ lymphocyte responses using dendritic cells transfected with messenger RNA amplified from tumor cells. Cancer Res. 60:1028-1034.

28. Gong, J., Chen, D., Kashiwaba, M., and Kufe, D. 1997. Induction of antitumor activity by immunization with fusion of dendritic and carcinoma cells. Nat. Med. 3:558-561.

29. Dietrich, W.F., et al. 1993. Genetic identification of Mom-1, a major modifier locus affecting Mininduced intestinal neoplasia in the mouse. Cell. 75:631-639.

30. Inaba, K., et al. 1993. Generation of large numbers of dendritic cells from mouse bone marrow cultures supplemented with granulocyte/macrophage colony-stimulating factor. J. Exp. Med. 176:1693-1702.

31. Inaba, K., et al. 1993. Granulocytes, macrophages and dendritic cells arise from a common major histocompatability complex class II-negative progenitor in mouse bone marrow. Proc. Natl. Acad. Sci. U. S. A. 90:3038-3042.

32. Homma, S., Toda, G., Gong, J., Kufe, D., and Ohno, T. 2001. Preventive antitumor activity against hepatocellular carcinoma (HCC) induced by immunization with fusions of dendritic cells and HCC cells in mice. J. Gastroenterol. 36:764-711.

33. Akasaki, Y., et al. 2001. Antitumor effect of immunizations with fusions of dendritic and glioma cells in a mouse brain tumor model. J. Immunother. 24:106-113.

34. Fong, L., and Engleman, E.G. 2000. Dendritic cells in cancer immunotherapy. Ann. Rev. Immunol. 18:245-273.

35. Lindner, M., and Schirrmacher, V. 2002. Tumour cell-dendritic cell fusion for cancer immunotherapy: comparison of therapeutic efficiency of polyethylene-glycol versus electro-fusion protocols. Eur. J. Clin. Invest. 32:207-217.

36. Gong, J., et al. 2000. Fusions of human ovarian carcinoma cells with autologous or allogeneic dendritic cells induce antitumor immunity. J. Immunol. 165:1705-1711. 
37. Guermonprez, P., Valladeau, J., Zitvogel, L., Thery, C., and Amigorena, S. 2002. Antigen presentation and $\mathrm{T}$ cell stimulation by dendritic cells. Annu. Rev. Immunol. 20:621-667.

38. Brunda, M.J., et al. 1996. Antitumor activity of interleukin 12 in preclinical models. Cancer Chemother. Pharmacol. 38:S16-S21.

39. Nastala, C.L., et al. 1994. Recombinant IL-12 administration induces tumor regression in association with IFN-gamma production. J. Immunol. 153:1697-1706.

40. Koido, S., Tanaka, Y., Chen, D., Kufe, D., and Gong, J. 2002. The kinetics of in vivo priming of CD4 and CD8 T cells by dendritic/tumor fusion cells in MUC1-transgenic mice. J. Immunol. 168:2111-2117.
41. Sasaki, S., et al. 1998. Human tumor growth suppression by apoptosis induced with anti-ErbB-2 chimeric monoclonal antibody. Jpn. J. Cancer Res. 89:562-570.

42. Gong, J., et al. 2000. Selection and characterization of MUC1-specific CD8 T cells from MUC1 transgenic mice immunized with dendritic-carcinoma fusion cells. Immunology. 101:1-13.

43. Gong, J., et al. 2000. Activation of antitumor cytotoxic $\mathrm{T}$ lymphocytes by fusions of human dendritic cells and breast carcinoma cells. Proc. Natl. Acad. Sci. U. S. A. 97:2715-2718.

44. Gong, J., et al. 2002. Immunization against murine multiple myeloma with fusions of dendritic and plasmacytoma cells is potentiated by interleukin 12. Blood. 99:2512-2517.
45. Hilkens, C.M., Kalinski, P., Boer, M.D., and Kapsenberg, M.L. 1997. Human dendritic cells require exogenous interleukin-12-inducing factors to direct the development of naive T-helper cells toward the Th1 phenotype. Blood. 90:1920-1926.

46. Buchanan, J.M., Vogel, L.A., Cleave, V.V., and Metzger, D.W. 1995. Interleukin 12 alters the isotype-restricted antibody response of mice to hen eggwhite lysozyme. Int. Immunol. 7:1519-1528.

47. Metzger, D.W., et al. 1996. Enhancement of humoral immunity by interleukin-12. Ann. N. Y. Acad. Sci. 795:100-115.

48. Nanni, P., et al. 2001. Combined allogeneic tumor cell vaccination and systemic interleukin 12 prevents mammary carcinogenesis in HER-2/neu transgenic mice. J. Exp. Med. 194:1195-1205. 